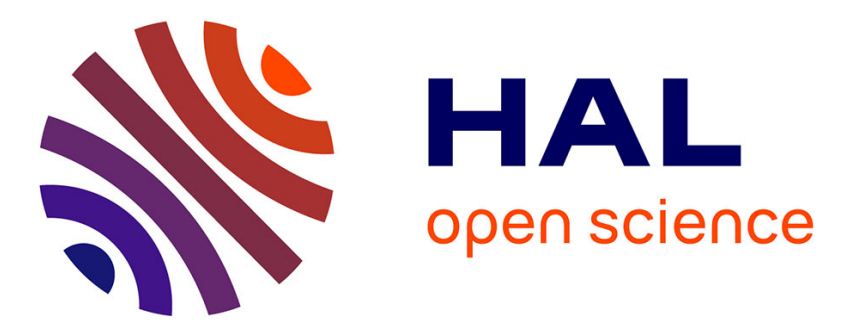

\title{
Calcium Phosphate Stone Morphology Can Reliably Predict Distal Renal Tubular Acidosis
}

Arnaud Dessombz, Letavernier Emmanuel, Jean-Philippe Haymann, Dominique Bazin, Michel Daudon

\section{- To cite this version:}

Arnaud Dessombz, Letavernier Emmanuel, Jean-Philippe Haymann, Dominique Bazin, Michel Daudon. Calcium Phosphate Stone Morphology Can Reliably Predict Distal Renal Tubular Acidosis. Journal of Urology, 2015, 193 (5), pp.1564-1569. 10.1016/j.juro.2014.12.017 . hal-01148416

\section{HAL Id: hal-01148416 https://hal.sorbonne-universite.fr/hal-01148416}

Submitted on 4 May 2015

HAL is a multi-disciplinary open access archive for the deposit and dissemination of scientific research documents, whether they are published or not. The documents may come from teaching and research institutions in France or abroad, or from public or private research centers.
L'archive ouverte pluridisciplinaire HAL, est destinée au dépôt et à la diffusion de documents scientifiques de niveau recherche, publiés ou non, émanant des établissements d'enseignement et de recherche français ou étrangers, des laboratoires publics ou privés. 
Calcium Phosphate Stone Morphology Can Reliably Predict Distal Renal Tubular Acidosis

Arnaud Dessombz, ${ }^{*}$ Emmanuel Letavernier, Jean-Philippe Haymann, Dominique Bazin and Michel Daudon

From the Centre national de la recherche, Laboratoire de Physique des Solides, Université Paris-11 (AD), Orsay and Institut national de la santé et de la recherche médicale, Unités mixtes de recherche 1138, Centre de Recherche des Cordeliers, Laboratoire de Physiopathologie Orale Moléculaire, Equipe Berdal, Université Paris5, Université Paris-6, Université Paris-7 (AD), Sorbonne Universités, Université Pierre et Marie Curie Paris-6 (EL, J-PH), Centre national de la recherche scientifique, Laboratoire de Chimie de la Matière Condensée de Paris, Université Pierre et Marie Curie Paris-6, Collège de France (DB), Assistance Publique-Hôpitaux de Paris, Service des Explorations Fonctionnelles and Institut national de la santé et de la recherche médicale, Unités mixtes de recherche S 1155, Hôpital Tenon (EL, J-PH, MD), Paris, France.

Purpose: Calcium stones represent $85 \%$ to $90 \%$ of all urinary calculi, including various crystalline compositions and etiological conditions. Calcium phosphate accounts for $10 \%$ to $15 \%$ of cases. These stones are mainly related to 3 groups of risk factors, including calcium or phosphate metabolism disturbance, renal acidification defects and urinary tract infection. Identifying the stone etiology often requires extensive metabolic evaluation. We assessed whether stone analysis including morphological typing in addition to stone composition could be a valuable help for diagnosis.

Materials and Methods: Of 60,564 stones analysed by morphological examination and infrared spectroscopy at our laboratory 6,439 (10.6\%) were mainly composed of carbapatite. Of these stone 1,093 patients were included in study who had an available etiological diagnosis and stones containing at least $70 \%$ of calcium phosphate without struvite.

Results: Of the 1,093 calcium phosphate stones $12.8 \%$ showed a peculiar morphology termed IVa2, characterized by a smooth aspect and a glazed brown yellow appearance with tiny cracks. This was associated with inherited distal renal tubular acidosis in $96.1 \%$ of cases. In contrast, the other stones of similar composition but different morphology were related to distal renal tubular acidosis in only $3.9 \%$ of cases. In addition, IVa2 stones were found in $65 \%$ of calcium phosphate stone formers associated with Sjögren syndrome and in 35\% of calcium phosphate stones in patients with medullary sponge kidney. These 2 conditions are related to a mild to moderate distal acidification defect.

Conclusions: Identifying IVa2 stone morphology is clinically relevant because it should prompt clinicians to search for complete or incomplete distal acidosis and initiate specific therapy to decrease recurrence.

KeyWords: kidney; nephrolithiasis; calcium phosphate; acidosis, renal tubular; diagnosis 


\section{Introduction}

Nephrolithiasis is a common disease affecting more than $10 \%$ of the population in Western countries with a high recurrence rate. The annual cost in the United States was \$2 billion in 2000 and it is increasing with time [1]. The causes are diverse, including dietary disequilibrium, urinary tract infection and metabolic disorders related to acquired or genetic diseases. Although stone classifications commonly distinguish only few chemical compounds, namely calcium, uric acid, cystine and infection stones, physical analysis may identify a wide variety of components. More than 100 mineral or organic compounds have been identified to date [2]. In industrialized countries and in an increasing number of developing countries socalled calcium stones account for about $90 \%$ of all urinary calculi with calcium oxalate the most frequent chemical species [3-5]. However, calcium stones can be divided into subgroups according to the main crystalline phase, which is often a strong marker of a specific urine composition [6]. Of the calcium phosphate stones those of carbapatite (crystallized carbonated hydroxyapatite) may result from urinary tract infection or metabolic factors such as hypercalciuria, phosphate leak or tubular acidification defects.

Although rare, some genetic or acquired diseases may be responsible for severe forms of urolithiasis associated with nephrocalcinosis and end stage renal failure, especially when the diagnosis is delayed. For example, in primary hyperoxaluria cases stone morphology and not composition could help with the diagnosis [7]. Thus, stone morphology appears to be a convenient, straightforward and useful examination to diagnose this rare but severe pathological composition while stone composition alone does not lead to the diagnosis.

Based on this background we hypothesized that other varieties of stones could benefit from morphological examination. An example would be calcium phosphate stones, which account for $10 \%$ to $15 \%$ of all calculi and result from urinary tract infections and/ or different metabolic disorders such as idiopathic hypercalciuria, hyperparathyroidism, phosphate leak, tubular acidosis or an excessive alkali load $[8,9]$.

The advantage of adding a stone morphology examination to infrared analysis is to provide a rapid, inexpensive orientation to specific pathological conditions that could not be readily identified when extensive metabolic investigations are not systematically performed. For example, in our experience the identification of typical IVa2 morphology led to the diagnosis of poorly symptomatic Sjögren syndrome with incomplete dRTA.

We sought to provide evidence that in addition to infrared spectroscopy, determining stone morphology is a key step in the diagnostic procedure of stone analysis that may identify sometimes unexpected metabolic or monogenic related stone diseases.

\section{Patients and Methods}

Of 60,564 stones analysed by morphological examination and infrared spectroscopy at our laboratory $6,439(10.6 \%)$ were mainly composed of calcium phosphate (more than $50 \%$ of the stone mass), including carbapatite, brushite, octacalcium phosphate pentahydrate, amorphous carbonated calcium phosphate or whitlockite. Of the stones 5,181 were mainly composed of carbapatite, representing $80.5 \%$ of calcium phosphate stones and $8.5 \%$ of the whole series. Stones containing any proportion of struvite, which more specifically indicates urinary tract infection with ureolytic microorganisms, were excluded from analysis. Because Calcium phosphate may be associated with a high proportion of calcium oxalate in a number of cases and, thus, be related to various metabolic conditions, we selected only stones containing an unambiguously high proportion of calcium phosphate, namely $70 \%$ of the whole stone content on infrared spectroscopy. Finally, we included in study only calculi 
associated with a detailed etiological diagnosis provided by physicians, which was available for 1,093 patients.

Of the relevant diagnoses dRTA was diagnosed first based on low serum bicarbonate, moderately low arterial $\mathrm{pH}$ (excluding pulmonary alkalosis), low urine ammonium, urine $\mathrm{pH}$ greater than 6.5 and in some cases a bicarbonate load test. In addition, when measured, urine citrate was low in the absence of urinary tract infection, commonly less than 0.7 mmol per 24 hours. The diagnosis of inherited dRTA was proven by DNA sequencing of the $\mathrm{Cl}^{-} \mathrm{HCO}_{3}^{-}$ exchanger gene (SLC4A1) or the $\mathrm{H}^{+}$adenosine triphosphatase gene (ATP6V0A4 or ATP6V1B1). MSK was diagnosed by computerized tomodensitometry or excretory urogram. Sjögren disease was diagnosed by at least 4 classic criteria, including a salivary gland biopsy based Chisholm score of greater than 3 and autoimmunity.

\section{Morphological Examination and Infrared Analysis}

Each calculus was studied using a stereomicroscope to define morphological type and structural characteristics as previously described.10 This also enabled the selection of representative parts of the stone for infrared analysis, such as the nucleus, the inner and external layers, and the surface [11]. Spectra were recorded by a Spectrospin Vector 22 Fourier transform infrared spectrometer (Bruker, Karlsruhe, Germany). Figure 1, a shows the $1 / 2 \mathrm{~F} 1$ typical spectra of carbapatite stones.

\section{SEM and Statistics}

A SUPRA 55-VP type environmental SEM (Carl Zeiss, Oberkochen, Germany) was used to observe the microstructure. This field effect gunmicroscope operates at 0.5 to $30 \mathrm{kV}$. High resolution observations were made using 2 secondary electron detectors, including an inlens secondary electron detector and an Everhart-Thornley secondary electron detector. An important feature of the environmental SEM compared to a conventional SEM is that nonconductive materials can be imagedwithout a conductive coating, which permits direct observation with no damage to the sample. The Fisher exact test was used for statistical comparison between groups. Statistical analysis was done with NCSS software.

\section{RESULTS}

While the infrared spectra of carbapatite stones were similar, the stones showed 2 morphological types (see Appendix and fig. 1, a to c). Stones of the first type, which was more common, had a homogenous rough surface and a poorly organized section of diffuse, whitish, concentric layers (fig. 1, b). The second type of stones showed a peculiar morphology characterized by a homogeneous smooth surface with a glazed appearance, bumps and cracks, and a heterogeneous inner organization of yellow-brown concentric foliated structures (fig. 1, c). In a previous morphoconstitutional classification of stones the 2 morphologies were termed types IVa1 and IVa2, respectively.10 The ultrastructure revealed by SEM confirmed a different stone pattern between the 2 morphological types (fig. 1, $\mathrm{d}$ and e). 

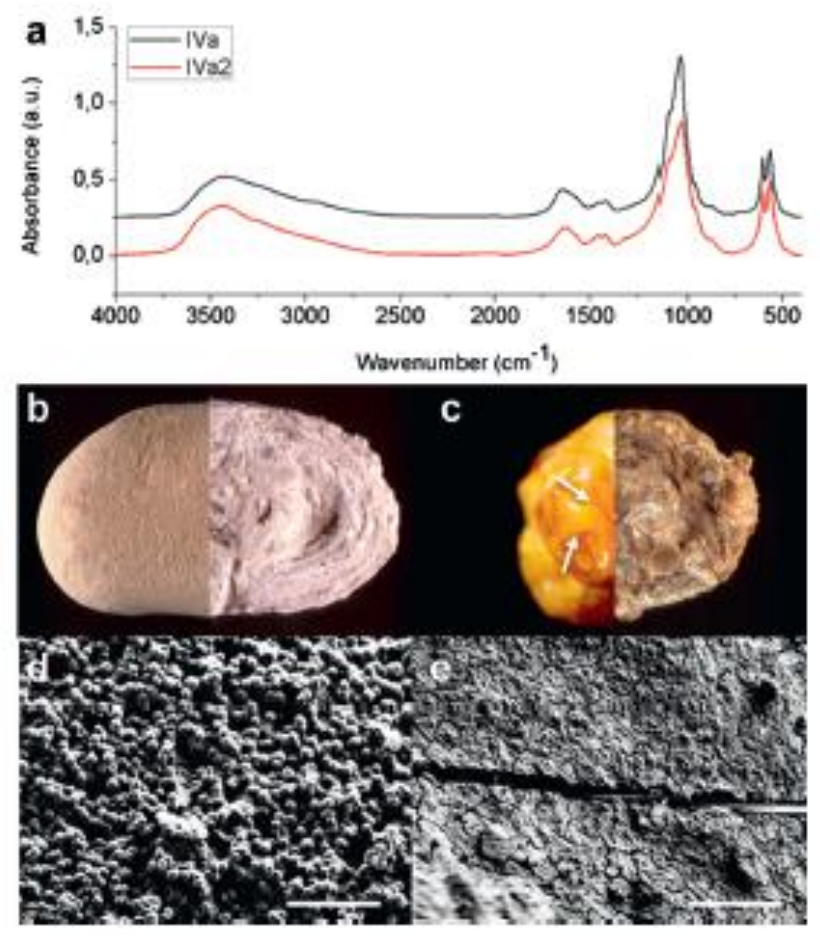

Figure 1. a, typical FTIR spectroscopy spectra of IVa2 and IVal type kidney stones. b, external and internal optical images of IVal type. $c$, external and internal optical images of IVa2 type. Arrows indicate surface cracks. d, SEM image shows type IVal. e, SEM image shows type IVa2. $d$ and e, scale bar indicates $10 \mu \mathrm{m}$.

Of the 1,093 stones containing more than $70 \%$ calcium phosphate IVa1 stones were more common $(87.2 \%$ of cases) than IVa2 stones. They were mainly related to chronic urinary tract infection in $39.6 \%$ of cases, hypercalciuria in $25 \%$, MSK in $17 \%$ and primary hyperparathyroidism in $9.8 \%$ (see table 1 ).

Table 1. IVa1 and IVa2 types among mainly Ca phosphate calculi by etiology ( $p<0.0001)$.

\begin{tabular}{|c|c|c|c|c|c|}
\hline \multirow[b]{2}{*}{ Etalog } & \multirow[b]{2}{*}{$\begin{array}{l}\text { No. } \\
\text { Stones }\end{array}$} & \multirow[b]{2}{*}{$\begin{array}{l}\text { Na. Pts } \\
\text { Na1 }(75]\end{array}$} & \multicolumn{3}{|c|}{ Wat } \\
\hline & & & $\begin{array}{c}\text { No. Pts } \\
{[\% !}\end{array}$ & $\begin{array}{c}y \\
\text { Sensitvity }\end{array}$ & Speoficity \\
\hline lnhented d7Th & 7 & $3 \quad$ Bg & 74 [9.1] & 96.1 & 935 \\
\hline Sjogren spondrame & 20 & 7 BSO & 13 [650] & 650 & 882 \\
\hline $\begin{array}{l}\text { Carburie anhiprase } \\
\text { inhibiturs (acetanolamide } \\
\text { ar topiramete) }\end{array}$ & 52 & $50 \quad 962$ & $2[8$. & 38 & 867 \\
\hline MS & 211 & $162(768)$ & $49[232$ & 232 & 897 \\
\hline Primary hypeparathyoidiam & 93 & $93(1000)$ & 0 & - & - \\
\hline Urinary taet infecton & $3 n$ & $37 \pi$ 9.5 & 2 10.5 & - & - \\
\hline Wiopatic hpecabiuria & 28 & 28 (1000) & 0 & - & - \\
\hline Phoshate lesk & 2 & $28(1000)$ & 0 & - & - \\
\hline Totals & $1,0 \mathrm{BS}$ & 953 [872] & 140 (128) & - & - \\
\hline
\end{tabular}


In contrast, IVa2 stones, representing only $12.8 \%$ of carbapatite stones, were associated with inherited dRTA in 52.9\% of cases, MSK in 35\% and Sjögren syndrome in $9.3 \%$. Thus, the specificity of IVa2 calculi for these 3 diseases was excellent at $94.3 \%$. The IVa2 type was found in $96.1 \%$ of the 77 cases of inherited dRTA diagnosed in this series vs less than $1 \%$ of IVa1 CA stones, representing $93.5 \%$ specificity $(\mathrm{p}<0.00001)$. Figure 2 shows the distribution $1 / 2 \mathrm{~F} 2$ of carbapatite stone types by etiology. In 3 cases the peculiar IVa2 stone morphology prompted us to search for inherited dRTA, which was confirmed by further metabolic evaluation. In another 3 cases the IVa2 stone morphology led to the diagnosis of Sjögren syndrome.

\section{DISCUSSION}

Kidney stones containing calcium phosphate are divided into 4 morphological types based on infrared analysis [2], including types IVa1 and IVa2-carbapatite, IVb-mixtures of carbapatite with other calcium or magnesium phosphates, IVc-struvite (excluded in this study) and IVd- brushite. A number of these stones are clearly distinguished by infrared analysis, for example brushite stones (IVd stones) or mixtures of various calcium and/or magnesium phosphates as in IVb stones. In the last 20 years we found a dramatic decrease in the incidence of infection stones related to urea-splitting bacteria while the proportion of IVb stones constantly decreased. Ambiguity remains for calcium phosphate stones mainly composed of carbapatite without struvite. As previously reported some of them may be related to urinary tract infection due to the high carbonate content found on infrared spectroscopy [12]. Carbapatite rich calcium phosphate stones may have 2 distinct morphologies (types IVa1 and IVa2) while the infrared spectra are often similar (fig. 1, a). We deliberately selected calculi mainly composed of carbapatite with a greater than $70 \%$ calcium phosphate level.

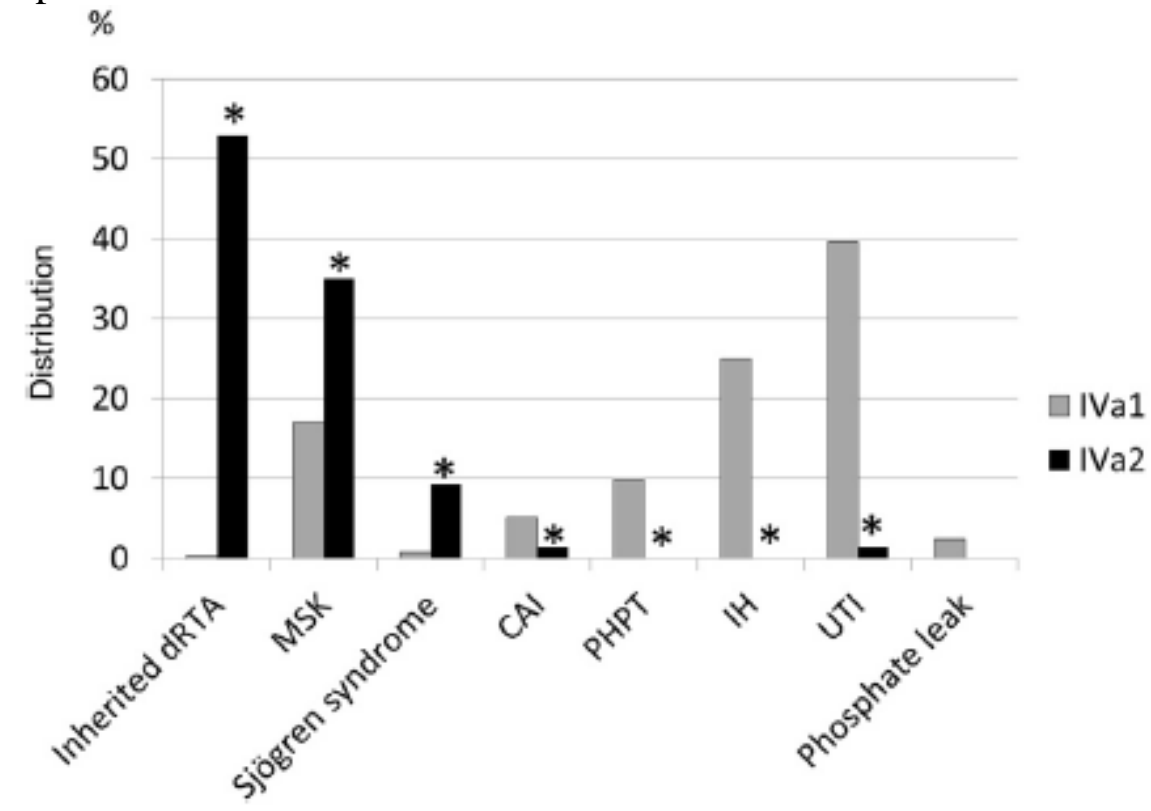

Figure 2. Carbapatite stone types by IVal and IVa2 etiology, including $0.3 \%$ and $52.9 \%$ for dRTA, $17.0 \%$ and $35.0 \%$ for MSK, $0.7 \%$ and $9.3 \%$ for Sjögren syndrome, $5.2 \%$ and $1.4 \%$ for carbonic anhydrase inhibitors (CAI ), 9.8\% and 0.0\% for primary hyperparathyroidism (PHPT), $25.0 \%$ and $0.0 \%$ for idiopathic hypercalciuria (IH ), 39.6\% and $1.4 \%$ for urinary tract infection (UTI), and $2.4 \%$ and $0.0 \%$ for phosphate leak, respectively. Asterisk indicates $p<0.001$ vs IVal. 
As noted in the current study IVa1 and IVa2 stones are associated with different pathological conditions. The main causes of IVa1 stones are those commonly reported in the literature for calcium phosphate stones, ie urinary tract infection, hypercalciuria and primary hyperparathyroidism [13-15]. In contrast, type IVa2 stones appear specific to inherited dRTA (see table). Interestingly IVa2 calculi are not associated with proximal tubular acidosis since stones in $96.2 \%$ of patients treated with carbonic anhydrase inhibitors, which induce proximal and distal tubular acidosis, were mainly type IVa1. Thus, IVa2 stone formation seems to depend on sustained high $\mathrm{pH}$ in the distal part of the nephron lumen, a setting present in dRTA due to $\mathrm{Hp}$ secretion defects [16]. The typical metabolic acidosis profile may be missing in incomplete dRTA. Sjögren syndrome and MSK are significantly associated with high urinary $\mathrm{pH}$ related to incomplete distal acidosis, ie an acidification defect affecting only the distal segment of some nephrons [17-19]. In 1 series a distal acidification defect was observed in up to $40 \%$ of patients with MSK [20]. However, another study failed to show evidence of an acidification defect in a significant proportion of patients with MSK [21]. In clinical practice the MSK diagnosis is difficult to assess by excretory urogram as suggested by discrepancies in the incidence of MSK in stone forming patients in the literature (range 3.5\% to $21 \%$ ) [22-24]. These discrepancies are due to various criteria used to diagnose MSK. Until the recent optimization of diagnostic methods based on computerized tomography the identification of MSK anatomical defects was complex [25]. In our experience calcium oxalate $(67.4 \%)$ and calcium phosphate $(26.7 \%)$ were the main component of stones in 576 patients with MSK (unpublished data). IVa2 stones were noted only in $8.2 \%$ of cases. Thus, MSK appears to be a heterogeneous entity. The previously demonstrated link between IVa2 and distal acidosis suggests that IVa2 stones in patients with MSK would be the hallmark of a local acidification defect responsible for incomplete renal tubular acidosis. In cohorts of patients with Sjögren syndrome renal involvement was estimated to be between $25 \%$ and $40 \% .26 \mathrm{e} 28 \mathrm{In}$ clinical practice it is not always easy to make the diagnosis because metabolic disorders may be absent or not specific, such as hypocitruria, which is a common finding in nephrolithiasis cases. Thus, hypocitruria is not pathognomonic for distal tubular defect because it is often found in patients with another condition such as urinary tract infection as well as in idiopathic calcium stone formers [29]. Moreover, Sjögren syndrome may be poorly symptomatic. In our experience identifying the typical IVa2 stone morphology led to the diagnosis in several cases.

Our series clearly shows the strong link between dRTA and IVa2. Among other etiologies we found a high rate of the IVa2 type in calcium phosphate stones in patients with Sjögren syndrome $(65 \%)$ or MSK $(23.2 \%)$, suggesting that patients with such a stone morphology have a defect of distal acidification. Thus, an early diagnosis first indicated by typical IVa2 stone morphology may have major clinical relevance.

The high prevalence of inherited or acquired dRTA in IVa2 stone group (136 patients or 97\%) may also explain why IVa2 stones are more active and recurrent than IVa1 stones. In our series $79.8 \%$ of patients with IVa2 stones had multiple recurrent stone episodes while the recurrence rate was only $54.7 \%$ in patients with IVa1 stones ( $\mathrm{p}<0.0001)$.

Thus, this high risk population deserves reinforced medical management that especially focuses on water and alkali intake. In contrast to IVal stones, no primary hyperparathyroidism, idiopathic hypercalciuria or phosphate leak (also called type III hypercalciuria) was observed in IVa2 stone cases. This provides interesting clinical clues and evidence that a high urinary calcium rate is not associated with this specific morphological type.

Our study has limitations. 1) It was based on a declarative diagnosis by physicians who completed a detailed form including all relevant diagnoses, limiting the study to 1,093 patients. 2) The MSK diagnosis is often complex. Incomplete distal tubular acidosis may be 
under diagnosed in the absence of an acidification test. It could be interesting to assess whether a IVa2 stone is a feature of underlying acidosis in MSK cases, which deserves further study.

\section{CONCLUSIONS}

To our knowledge our data address a new paradigm in stone disease and demonstrate the interest in stone morphology analysis in addition to composition, as recently suggested by Williams and McAteer [30]. For the patient it appears highly effective and beneficial to assess an unexpected etiology that is often responsible for recurrent calculi and/or progressive renal failure, or to link/exclude stone disease using metabolic or pathological findings. For the first time to our knowledge our study shows the strong, specific link between dRTA and carbapatite stone morphological type IVa2 irrespective of the cause of dRTA. Notably stone disease may be the most prominent sign of acquired tubular acidosis before extrarenal manifestations. In such cases stone morphology provides strong evidence of dRTA.

Thus, it allows for early diagnosis and subsequent early medical management, which helps prevent the progression of chronic kidney disease. In addition to infrared spectroscopy analysis, stone morphology appears to be a major analytical step to make an etiological diagnosis of calcium phosphate kidney stones, as previously illustrated for calcium oxalate monohydrate stones in primary hyperoxaluria cases [7].

\section{APPENDIX}

Main morphological differences between IVa1 and IVa2 stone types.

\begin{tabular}{lll}
\hline \multicolumn{1}{c}{ Stone Morphological Characteristics } & \multicolumn{1}{c}{ IVa1 } & \multicolumn{1}{c}{ IVa2 } \\
\hline Surface: & Rough & Smooth \\
Aspect & Rare & Common \\
Bumps & No & Yes \\
Glazed appearance & No & Yes \\
$\begin{array}{l}\text { Tiny cracks } \\
\text { Color }\end{array}$ & Whitish to beige & Brown-yellow \\
$\begin{array}{l}\text { Section: } \\
\text { Crumbly, poorly organized or homogenous, } \\
\quad \text { diffuse whitish concentric layers }\end{array}$ & Yes & No \\
$\begin{array}{l}\text { Foliated structure of thin whitish layers } \\
\quad \text { alternating with thick brown-yellow } \\
\quad \text { layers }\end{array}$ & No & Yes \\
Glazed appearance & & \\
\hline
\end{tabular}

\section{REFERENCES}

1. Brikowski TH, Lotan Y and Pearle M: Climate related increase in the prevalence of urolithiasis in the United States. Proc Natl Acad Sci USA 2008; 105: 9841.

2. Daudon M and Jungers P: Stone composition and morphology: a window on etiology. In:

Urolithiasis: Basic Science and Clinical Practice. Edited by JJ Talati, HG Tiselius, DM Albala et al. London: Springer Verlag 2012; pp 113e141.

3. Osther PJS: Epidemiology of kidney stones in the European Union. In: Urolithiasis: Basic Science and Clinical Practice. Edited by JJ Talati, HG Tiselius, DM Albala et al. London: Springer Verlag 2012; pp 3e12.

4. Denstedt JD and Fuller A: Epidemiology of stone disease in North America. In: Urolithiasis: Basic Science and Clinical Practice. Edited by JJ Talati, HG Tiselius, DM Albala et al. London: Springer Verlag 2012; pp 13e20. 
5. Deyi Luo D, Hong Li $\mathrm{H}$ and Wang K: Epidemiology of stone disease in China. In: Urolithiasis: Basic Science and Clinical Practice. Edited by JJ Talati, HG Tiselius, DM Albala et al. London: Springer Verlag 2012; pp 53e60.

6. Daudon M, Labrunie M, Hennequin C et al: Relative influence of calcium and oxalate urine concentration on the risk of calcium oxalate crystallization. In: Renal Stone Disease. Crystallization Process, Pathophysiology, Metabolic Disorders and Prevention. Edited by P Jungers and M Daudon. Paris: Elsevier 1997; pp 72e73.

7. Daudon M, Jungers $\mathrm{P}$ and Bazin D: Peculiar morphology of stones in primary hyperoxaluria. N Engl J Med 2008; 359: 100.

8. Gault MH, Parfrey PS and Robertson WG: Idiopathic calcium phosphate nephrolithiasis. Nephron 1988; 48: 265.

9. Daudon M, Bader C and Jungers P: Urinary calculi: review of classification methods and correlations with etiology. Scanning Microsc 1993; 7: 1081.

10. Estepa L and Daudon M: Contribution of Fourier transform infrared spectroscopy to the identification of urinary stones and kidney crystal deposits. Biospectroscopy 1997; 3: 347.

11. Carpentier X, Daudon M, Traxer O et al: Relationships between carbonation rate of

carbapatite and morphologic characteristics of calcium phosphate stones and etiology. Urology 2009; 73: 968.

12. Maurice-Estepa L, Levillain P, Lacour B et al: Crystalline phase differentiation in urinary calcium phosphate and magnesium phosphate calculi. Scand J Urol Nephrol 1999; 33: 299.

13. Hesse A and Heimbach D: Causes of phosphate stone formation and the importance of metaphylaxis by urinary acidification: a review. World J Urol 1999; 17: 308.

14. Evan AE, Lingeman JE, Coe FL et al: Histopathology and surgical anatomy of patients with primary hyperparathyroidism and calcium phosphate stones. Kidney Int 2008; 74: 223. 15. Lin DF, Yan SM, Zhao Y et al: Clinical and prognostic characteristics of 573 cases of primary Sj€ogren's syndrome. Chinese Med J 2010; 123: 3252.

16. Kassan S and Moutsopoulos H: Clinical manifestations and early diagnosis of Sjögren syndrome. Arch Intern Med 2004; 164: 1275.

17. Fulop M and Mackay M: Renal tubular acidosis, Sjögren syndrome, and bone disease. Arch Intern Med 2004; 164: 905.

18. Wrong OM, Feest TG and MacIver AG: Immunerelated potassium-losing interstitial nephritis: a comparison with distal renal tubular acidosis. Q J Med 1993; 86: 513.

19. Higashihara E, Nutahara K, Tago et al: Medullary sponge kidney and renal acidification defect. Kidney Int 1984; 25: 453.

20. Ginalsky JM, Portmann L and Jaeger P: Does medullary sponge kidney cause nephrolithiasis? AJR Am J Roentgenol 1990; 155: 299.

21. Fabris A, Lupo A, Bernich P et al: Long-term treatment with potassium citrate and renal stones in medullary sponge kidney. Clin J Am Soc Nephrol 2010; 5: 1663.

22. Wikstr€om B, Backman U, Danielson BG et al: Ambulatory diagnostic evaluation of 389 recurrent renal stone formers. A proposal for clinical classification and investigation. Klin Wochenschr 1983; 61: 85.

23. Laube M, Hess B, Terrier F et al: Prevalence of medullary sponge kidney in patients with and without nephrolithiasis. Praxis 1995; 84: 1224.

24. Yendt ER: Medullary sponge kidney. In: Diseases of the Kidney. Edited by RW Schrier and CW Gottschalk. Boston: Little-Brown 1988; vol II, p 573.

25. Gambaro G, Danza FM and Fabris A: Medullary sponge kidney. Curr Opin Nephrol Hypertens 2013; 22: 421.

26. Zhao Y, Dong Y, Guo XP et al: Clinical analysis of primary Sjögren's syndrome. Beijing Med 1997; 19: 100. 
27. Garcia-Carrasco M, Ramos-Casals M, Rosas J et al: Primary Sjögren syndrome: clinical and immunologic disease patterns in a cohort of 400 patients. Medicine 2002; 81: 270.

28. Skopouli FN, Dafni U, Ioannidis JP et al: Clinical evolution, and morbidity and mortality of primary Sjögren's syndrome. Semin Arthritis Rheum 2000; 29: 296.

29. Pak CY: Citrate and renal calculi: an update. Miner Electrolyte Metab 1994; 20: 371.

30. Williams JC Jr and McAteer JA: Retention and growth of urinary stones: insights from imaging. J Nephrol 2013; 26: 25. 